\title{
ESTÁGIO SUPERVISIONADO NO CURSO DE LICENCIATURA DE LETRAS NO IFES: DESAFIOS, DEBATES E PROPOSTAS NA FORMAÇÃO INICIAL
}

\author{
SUPERVISED INTERNSHIP IN PORTUGUESE LANGUAGE \\ GRADUATION COURSE AT IFES: CHALLENGES, DEBATES AND \\ PROPOSALS FOR INITIAL TRAINING
}

\begin{abstract}
Selma Lúcia de Assis Pereira *
Resumo: A proposta desse artigo é dar visibilidade às ações oferecidas para a formação inicial do docente em Curso de Licenciatura em Letras dentro dos Institutos Federais (IFs), aos avanços durante sua formação e às possíveis propostas para uma educação mais coletiva, participativa e de qualidade. Os procedimentos metodológicos basearam-se, principalmente, em coleta de relatos orais e escritos, obtidos por meio de relatórios preenchidos de forma sistematizada durante o desenvolvimento da disciplina curricular Estágio Supervisionado. Estes dados constituem o corpus do trabalho. Como abordagem teórica, priorizamos os estudos realizados por Pimenta (2015), Pimenta e Lima (2012), Barreiro e Gebran (2006) e Rodrigues (2015). Os resultados alcançados foram pertinentes para a nossa reflexão sobre o ensino-aprendizagem da língua materna e para a formação inicial docente. O Estágio se mostrou eficaz por proporcionar liberdade, um espaço de reflexão e manifestação das experiências daqueles(as) que se tornarão futuros docentes.
\end{abstract}

Palavras-chave: Estágio Supervisionado. Licenciatura. Formação de Professores.

Abstract: The purpose of this article is to give visibility to the actions offered for the initial teachers' training in a Bachelor's Degree in Portuguese Language within the Federal Institutes (IFs), to the advances during their formation and to possible proposals to promote a more collective and participatory education. This course takes place in a space dedicated to training technicians and bachelors in other areas other than humanities. The methodological procedures were mainly based on oral and written reports collected during the development of the Supervised Internship. As theoretical approach we based on Pimenta (2015), Pimenta and Lima (2012), Barreiro and Gebran (2006) and Rodrigues (2015). The results were relevant to our reflection on the teaching-learning of the mother tongue and for the initial teacher training. The Internship proved to be effective in providing freedom, a space for reflection and manifestation of the experiences of those who will become future teachers.

Keywords: Supervised Internship. Degree. Teacher Training.

\section{Introdução}

Iniciamos o nosso estudo com um olhar cuidadoso e criterioso no intuito de buscar perceber e se apropriar do espaço em que estamos inseridos. Fazemos parte de um curso de Letras em sua primeira turma de formação, curso este concebido em um IF no interior do Estado do Espírito Santo. Estamos localizados em uma cidade de pouco mais de 25 mil habitantes que, meio desconfiados, observaram o surgimento do campus e seus impactos sócio-econômico-culturais. Diante desses dados, surge em 2016 a

\footnotetext{
* Professora do Curso de Licenciatura em Letras-Português do Instituto Federal do Espírito Santos (IFES) campus Venda Nova do Imigrante - ES. Mestra em Educação pela Universidade Federal do Espírito Santo (UFES). Coordenadora da Pós-Graduação Lato Sensu em Práticas e Processos Educativos (IFES-Venda Nova do Imigrante) e membro do Grupo de Pesquisa Cultura Escolares, Saberes, Práticas e Processos Educativos (GPCESPPE) - (IFES-Venda Nova do Imigrante). E-mail: selma.pereira@ifes.edu.br
} 
oportunidade de expandir a oferta do campus com uma graduação de licenciatura. Realizada a pesquisa de campo e audiências públicas, chegou-se à conclusão de que seria um Curso de Licenciatura em Letras-Português, para atender a escassez de profissionais formados para a demanda das escolas municipais e estaduais da região.

A proposta dessa pesquisa é dar visibilidade às ações oferecidas para a formação inicial do docente em Curso de Licenciatura em Letras dentro dos IFs, bem como aos avanços durante sua formação e às possíveis propostas de ação para a melhoria de se fazer uma educação mais coletiva, participativa e de qualidade, em um espaço consagrado em formar técnicos e bacharéis de outras áreas que não sejam das humanas. Os procedimentos metodológicos basearam-se em relatos orais e escritos, coletados por meio de relatórios preenchidos e rodas de conversa, de forma sistematizada, durante o desenvolvimento da etapa de docência compartilhada realizada pela turma do $6^{\circ}$ período de 2019/1, na disciplina Estágio Supervisionado. Estes dados constituem o corpus do trabalho. Como abordagem teórica, utilizamos os estudos realizados por Pimenta (2015), Pimenta e Lima (2012), Barreiro e Gebran (2006) e Rodrigues (2015).

O objetivo do Curso de Letras, segundo o Projeto Pedagógico do Curso (PPC) 2016, é oferecer aos discentes a oportunidade de refletir temas pertinentes à teoriaprática, tanto no âmbito específico das Letras como também no âmbito da educação. Essa característica se dá pela importância de uma consciência ampla ao futuro docente, podendo perceber a diversidade que encontrará em sua profissão e, assim, contribuir para reflexão, pesquisa, ação e propostas de intervenção na educação.

Diante disso, é fundamental compreendermos o conceito do Estágio Supervisionado nas licenciaturas, que, com o passar dos tempos, foi se transformando em uma disciplina de formação de acompanhamento de prática para uma disciplina obrigatória de formação, conforme prevê a legislação. Posteriormente, apresentaremos os desafios e os avanços dessa disciplina em um curso de Letras no IFES, bem como possíveis propostas de se fazer uma formação inicial docente em um IF.

\section{Breve percurso da legislação do Estágio Supervisionado}

O Estágio Supervisionado dentro dos IFs teve seus confrontos e desafios uma vez que, ao atender aos diferentes interesses, se formavam verdadeiras arenas de disputas. Conforme os estudos de Melo e Guedes (2019, p. 436) “(...) os históricos debates em torno da legislação sobre estágio explicitam a existência de um confronto entre aqueles que defendiam o estágio, com base no interesse da escola, e os que visavam somente o interesse das empresas". Essa característica é visível nos espaços formativos de licenciatura dos IFs. Utilizamos como base os estudos de Melo e Guedes (2019) nesse retrospecto. Segundo Sobrinho (2008), a história do Estágio Supervisionado inicia-se durante a década de 1940, quando Getúlio Vargas assina o Decreto-Lei $n^{\circ}$ 4073/42, que estabelece a Lei Orgânica do Ensino Industrial, tornando-se assim a primeira lei de estágio no Brasil. Nesse decreto foram estabelecidas as bases de organização dos estudos, pelo regime do ensino industrial, visando à preparação profissional de trabalhadores para a indústria, atividades artesanais e trabalhadores dos transportes, das comunicações e da pesca (BRASIL, 1942, p.1). Para Melo e Guedes (2019), a legislação que regulamenta o Estágio Supervisionado nos IFs inicia-se com esse decreto até a Lei $\mathrm{n}^{\mathrm{o}} 11.788 / 2008$. 
Seguindo a linha do tempo por Melo e Guedes (2019), nos anos 1970, o governo de Emílio Garrastazu Médici, por meio do Decreto $n^{\circ}$ 66.546/1970, criou a Coordenação do Projeto Integração, que estabeleceu para os alunos do ensino superior o programa de estágios práticos, direcionado aos cursos de : Engenharia, Economia, Administração e Tecnologia. Ainda na década de 1970, precisamente em 1977, o Presidente da República Ernesto Geisel, sanciona a Lei No 6.494/1977 que "Dispõe sobre os estágios de estudantes de estabelecimento de ensino superior e do $2^{\circ}$ Grau e Supletivo e dá outras providências". Essa Lei culminou em situações irregulares de contratação de estagiários, facilitando o surgimento do subemprego. Apenas em 1982, com o Decreto $n^{\circ}$ 87.497/82, houve a regulamentação da Lei 6.494/1977, ambos foram revogados somente em 1994.

A partir da Lei de Diretrizes e Bases da Educação Nacional (LDB), nº 9.394/96, que instituiu a maneira e a forma de ensino a ser avaliada pelos resultados de aprendizagem, a educação escolar enfocou o desenvolvimento de competências cognitivas e profissionais vinculadas "ao mundo do trabalho e à prática social" (BRASIL, 1996). Houve o entendimento e um esforço de se pensar o Estágio Supervisionado como uma disciplina curricular de ensino e aprendizagem formal entre a teoria e a prática.

Em 2008, foi revogado pela Lei $\mathrm{n}^{\mathrm{o}} 11.788 / 2008$ o último parágrafo da LDB, instituindo a nova Lei do Estágio de Estudantes preconizando que: "Os sistemas de ensino estabelecerão as normas de realização de estágio em sua jurisdição, observada a lei federal sobre a matéria". Em seu artigo $1^{\circ}$ e respectivos parágrafos, lê-se:

\begin{abstract}
Art. 1. Estágio é ato educativo escolar supervisionado , desenvolvido no ambiente de trabalho, que visa à preparação para o trabalho produtivo de educandos que estejam frequentando o ensino regular em instituições de educação superior, de educação profissional, de ensino médio, da educação especial e dos anos finais do ensino fundamental, na modalidade profissional da educação de jovens e adultos.

$\S 1$. O estágio faz parte do projeto pedagógico do curso, além de integrar o itinerário formativo do educando. $\S 2$. O estágio visa ao aprendizado de competências próprias da atividade profissional e à contextualização curricular, objetivando o desenvolvimento do educando para a vida cidadã e para o trabalho (BRASIL, 2008, p.1).
\end{abstract}

Pode-se observar que o Estágio Supervisionado ganha um status de componente do Projeto Pedagógico do Curso (PPC), integrado ao itinerário formativo do discente. Esse componente passou a enfocar, então, o aprendizado de competências e habilidades próprias da atividade profissional, a fim de desenvolvê-lo para a realidade tendo, dessa forma, como objetivo o trabalho e a cidadania.

Neste contexto, Melo e Guedes (2019) mencionam as Diretrizes Curriculares Nacionais para a Formação de Professores (DCNs) (BRASIL, 2015), em que compreendemos que o Estágio Supervisionado se constitui em uma articulação indissociável entre o saber e o fazer, tornando-se objeto da práxis educativa. Segundo os estudos de Pimenta e Lima (2012), o Estágio Supervisionado é uma integração entre a teoria e a prática, e não entre teoria ou a prática, com o enfoque principal de fortalecer a formação inicial do futuro docente.

É importante ressaltar que nessas DCNs para Formação de Professores define-se, em seu artigo 13, a estrutura e o currículo da formação inicial do magistério na educação 
básica, sendo no mínimo 3.200 horas, e desse total 400 horas são destinadas ao Estágio Supervisionado, considerando-o como componente obrigatório (BRASIL, 2015).

Nessa direção, o Instituto Federal do Espírito Santo, por meio do seu Conselho Superior, dispõe a regulamentação dos estágios dos alunos da Educação Profissional Técnica de Nível Médio e da Educação Superior, CS n. 58, de 17 de dezembro de 2018 que institui:

Art. 2 O estágio é considerado um ato educativo escolar supervisionado, desenvolvido no ambiente do trabalho, que visa à preparação para o trabalho produtivo de educandos que estejam frequentando o ensino regular na Educação Profissional, Técnica de Nível Médio e na Educação Superior, oferecido pelo Ifes nas modalidades presencial e à distância.

$\S 1^{\circ} \mathrm{O}$ estágio faz parte do projeto pedagógico do curso, além de integrar o itinerário formativo do educando.

$\S 2^{\circ} \mathrm{O}$ estágio visa ao aprendizado de competências próprias da atividade profissional e à contextualização curricular, promovendo:

I. o relacionamento dos conteúdos e contextos para dar significado ao aprendizado;

II. a integração à vivência e à prática profissional ao longo do curso;

III. a aprendizagem social, profissional e cultural para o desenvolvimento do educando para a vida cidadã e para o trabalho;

IV. a participação em situações reais de vida e de trabalho em seu meio;

V. o conhecimento dos ambientes profissionais;

VI. condições necessárias à formação do aluno no âmbito profissional;

VII. familiarização com a área de interesse de atuação do futuro profissional;

VIII. contextualização dos conhecimentos gerados no ambiente de trabalho para a reformulação dos cursos.

IX. a inclusão do aluno com necessidades específicas no mercado de trabalho [...] (Resolução CS no 58, 17/12/2018).

Percebe-se que a normativa, em seu $2^{\circ}$ artigo, tem o Estágio Supervisionado como um ato educativo que visa à preparação dos educandos para o trabalho produtivo. Observa-se que trata dos educandos do nível técnico e do nível superior, enfatizando a relação entre teoria e prática, familiarização e contextualização - não muito diferente do que percebemos nos primórdios do que se entende por estágio. O que nos chama a atenção é que a Educação Superior é colocada de maneira abrangente, não atendendo as peculiaridades das licenciaturas, abrindo lacunas para preenchimento de registros dos discentes, uma vez que a redação desses registros está voltada para o discurso empresarial e comprometendo consequentemente a disseminação de resultados de pesquisas. Isso ocorre porque a Resolução do CS n 58 de 17/12/2018 trata do Estágio Supervisionado no Ensino Superior de maneira ampla e generalizada, conforme percebemos nos artigos relacionados:

Art. $5^{\circ}$

O estágio poderá ser obrigatório elou não obrigatório, conforme determinação das diretrizes curriculares da etapa, modalidade, área de ensino e do projeto pedagógico do curso.

Art. $6^{\circ}$

Estágio obrigatório é aquele definido como tal no projeto pedagógico do curso, cuja carga horária é requisito para aprovação e obtenção do diploma e seu início só poderá acontecer atendendo aos seguintes 
requisitos mínimos, desde que respeitadas as prerrogativas do projeto pedagógico de cada curso [...]".

$\S 1^{\circ} \mathrm{Na}$ educação superior, as atividades de extensão, monitorias e iniciação científica poderão ser equiparadas ao estágio obrigatório caso esteja previsto no projeto pedagógico do curso.

$\S 2^{\circ}$ As atividades profissionais desenvolvidas pelo estudante, na educação superior e na profissional técnica de nível médio, poderão ser equiparadas ao estágio obrigatório caso esteja previsto no projeto pedagógico do curso. [...] (Resolução do CS n ${ }^{\circ} 58$ de 17/12/2018).

Entendemos que o Estágio Supervisionado é um período de aprendizagem, em que o futuro docente terá a oportunidade de ver-se e fazer-se professor. Como afirma Rodrigues (2015 p. 9), "O estágio é considerado como um componente fundamental na formação profissional, e como um dos espaços específicos para a formação do docente crítico-reflexivo e na construção dos saberes docentes necessários à sua profissão".

Depois dessa breve contextualização sobre a conceituação do Estágio Supervisionado, apresenta-se aqui uma descrição da nossa atuação frente ao desafio da tarefa de conduzir e desenvolver a formação inicial dos docentes em um Curso de Licenciatura em Língua Portuguesa, do IFES - Campus Venda Nova do Imigrante, localizado no município de Venda Nova do Imigrante, no interior Sul do Espírito Santo. A motivação para o desenvolvimento deste estudo é a tentativa de dar visibilidade ao nosso esforço e empenho na formação desses educadores visando, sempre, entregar à sociedade profissionais bem preparados, críticos do seu ser-fazer e responsáveis, mesmo em um ambiente cercado por cursos da área de exatas, como acontece nos IFs.

\section{Estágio Supervisionado no Curso de Licenciatura em Letras/Português no IFES}

Mediante ao desafio de se fazer uma formação inicial docente atendendo à legislação vigente com carga horária de $400 \mathrm{~h}$, e com o intuito de entregar à sociedade profissionais bem preparados, organizamos um caminho a ser percorrido para o referido Curso de Licenciatura em Letras Português no IFES. Esse percurso se divide em três momentos de Estágio Supervisionado: Estágio Supervisionado I, com 160h, voltado para os anos finais do Ensino Fundamental II; Estágio Supervisionado II, com 120h, voltado para o Ensino Médio e Estágio Supervisionado III, podendo o discente escolher em qual etapa quer se aprofundar.

A pesquisa foi realizada durante as aulas da disciplina curricular de Estágio Supervisionado, no primeiro semestre de 2019, por meio de análise e observação dos relatos orais e escritos produzidos pelos discentes, no período de investigação nas escolas-campo. A disciplina curricular estabelece etapas a serem seguidas, com a finalidade de instigar a percepção investigativa do discente, que compreendem cinco tipos de atividades, a saber:

1. Reflexão teórica (atividades curriculares);

2. Revisão da observação e análise da realidade;

3. Atividades de coparticipação;

4. Docência compartilhada e regência de classe e

5. Elaboração do relatório final. 
Entendemos que a reflexão teórica nos permite considerar o que os nossos discentes encontrarão na realidade das escolas. Muitos deles são oriundos dos municípios da região e acabaram de sair do Ensino Médio e, por isso, a relação entre professor e aluno na perspectiva tradicional ainda é muito viva em seus pensamentos e correlações sendo, muitas vezes, inevitáveis.

O corpus de nossa pesquisa foi composto pelos relatos orais e escritos dos discentes sobre sua atuação nas escolas-campo. É por isso que a reflexão das teorias, à luz da perspectiva de inovação e da reflexão sobre o quê e como ensinar a língua materna, fazendo conexão com as demais disciplinas curriculares do curso, faz-se importante para desmitificar a dicotomia entre teoria-prática para esse discente-jovempesquisador.

Segundo os estudos de Pimenta e Lima (2012), é possível verificar que há muito que se fazer para minimizar o percurso da realização do estágio, no que tange à teoria e à prática. Por meio das observações nos relatos dos discentes, durante sua atuação e coparticipação, evidenciamos a principal dificuldade do estágio como sendo $\mathrm{o}$ distanciamento entre teoria e prática, como descrito no trecho:

$\mathrm{O}$ reducionismo dos estágios às perspectivas da prática instrumental e do criticismo expõe os problemas na formação profissional docente. A dissociação entre teoria e prática aí presente resulta em um empobrecimento das práticas nas escolas, o que evidencia a necessidade de explicitar porque o estágio é teoria e prática (e não teoria ou prática) (PIMENTA; LIMA, 2012, p. 41).

Nesse sentido, o objetivo do estágio é fazer com que a teoria esteja aliada à prática. Para esse fim, propusemos que durante nossas aulas teóricas, teríamos um período para nossas discussões, em formato de roda de conversa que, com o passar do tempo, chamamos de Estágio Terapia. Era o momento de colocarmos nossas angústias em relação ao que se aprendia nas disciplinas do curso e a realidade da escola. Dessa forma, por meio do diálogo, deixávamos o sentimento de ser um fardo pesado quando se pensa e se faz educação. Pimenta e Lima afirmam que:

[...] o papel das teorias é iluminar e oferecer instrumentos e esquemas para a análise e investigação que permitam questionar as práticas institucionalizadas e as ações dos sujeitos e, ao mesmo tempo, colocar elas próprias em questionamento, uma vez que as teorias são explicações sempre provisórias da realidade (PIMENTA; LIMA, 2012, p. 43).

Como a teoria vem para iluminar e oferecer instrumentos para a investigação, partimos para o segundo passo do nosso caminho que é a coparticipação. Os discentes são instigados a colaborar com o professor-tutor, a fim de que ele possa desenvolver-se e perceber o tempo do processo de ensino-aprendizagem, as ferramentas e metodologias a serem pensadas e desenvolvidas e a avaliação a ser construída. Assim, conceber uma base sólida para que se elabore um pensamento crítico e reflexivo da realidade. Muitos dos nossos discentes puderam perceber que esse momento é muito importante nas práticas pedagógicas, conforme Pimenta e Lima pontuam:

Ao transitar da universidade para a escola e desta para a universidade, os estagiários podem tecer uma rede de relações, conhecimentos e aprendizagens, não com o objetivo de copiar, de criticar apenas os modelos, 
mas no sentido de compreender a realidade e ultrapassá-la (PIMENTA; LIMA, 2012, p. 111).

Em nossos momentos de reflexão acerca do ensino da língua, da escolha de textos e autores e de abordagens metodológicas, pudemos analisar o quanto havia o desejo de se fazer algo inovador. No entanto, verificamos, também, o quanto nossas escolas ainda estão presas aos modelos e métodos tradicionais não muito abertos a uma nova maneira de pensar a língua materna e seu ensino.

É relevante pontuar que os relatos orais e escritos ilustrados nesse trabalho foram frutos de um conhecimento adquirido, e muito debatido durante as aulas da disciplina Estágio Supervisionado, em nossas rodas de conversas, que por muitas vezes trouxeram as frustrações e as esperanças do fazer-ser professor. Como metodologia de coleta de dados, os discentes, além de apresentarem oralmente as vivências em seu Estágio Supervisionado, entregaram os relatos escritos embasados nas teorias estudadas. Participaram 16 (dezesseis) discentes da disciplina curricular, distribuídos em 6 (seis) escolas-campo, sendo 3 (três) no município onde se encontra o campus Venda Nova do Imigrante e 3(três) em diferentes municípios vizinhos. Os relatos escritos selecionados foram coletados no momento da experiência da docência compartilhada, a última etapa da disciplina curricular como resultado final. Trata-se de um olhar coletivo para se pensar na docência e nos seus desafios, como podemos perceber nos excertos abaixo:

\begin{abstract}
Acreditamos que o momento é oportuno para aproveitar as práticas boas do professor tutor e pensar em maneiras de reformular as que não são tão boas. (..) Nesse sentido, consideramos indispensável a oportunidade de conhecer a realidade da sala de aula e das práticas do professor, para, a partir disso, formularmos o nosso modelo de aula (Discente do $6^{\circ}$ período 2019/1, grifos da autora).
\end{abstract}

Observamos, por meio do relato da discente, que muitas escolas estão ainda pautadas em paradigmas e fórmulas baseadas em uma perspectiva fundamentada em reproduzir o conteúdo, fazendo com que nosso olhar de pesquisador e investigador da realidade nos leve a repensar e rever as futuras práticas desses discentes. Uma atividade desafiadora, uma vez que o ensino de Língua Portuguesa se pauta em frentes - ensino da língua, produção textual e literatura - que o docente pode desenvolver simultaneamente, dependendo dos seus objetivos, considerando os desafios do mundo globalizado e das condições sócio-econômico-sociais das famílias. Eis o que é relatado:

\footnotetext{
A reflexão também possibilita fazer algumas indagações sobre como deve ser a prática ou as práticas docentes mais adequadas para evitar o fracasso escolar. Acreditamos que esse seja o grande desafio da docência. Já para os professores, alguns fatores revelam os desafios enfrentados: o mundo atual, dinâmico e instantâneo, ocasionado pelo advento da internet, as famílias cada vez mais desestruturadas e ausentes, o sucateamento da educação, dentre outros. (...) Nesse cenário, tem ficado a cargo da escola a tentativa de dirimir os problemas da formação (acadêmica e humanística) dos jovens, papel injusto, pois requer responsabilidades que deveriam ser de todos (Discente do $6^{\circ}$ período 2019/1, grifos da autora).
}

Os estudos realizados por Pozzobon, Mahendra, Marin (2017) apresentam a preocupação com o termo "fracasso escolar". Em sua pesquisa intitulada Renomeando o fracasso escolar, buscaram compreender como os pais, os alunos e os professores 
entendiam o termo fracasso escolar e por qual outro termo seria mais adequado renomeá-lo a partir de reflexões e sugestões dos participantes da pesquisa. No item que tratou sobre responsabilização dos pais, dos alunos e dos sistemas tem-se que:

(...) deve nos remeter a um olhar mais amplo, considerando vários fatores responsáveis pelo fracasso escolar, como estrutura escolar macro e micro, o sistema em geral, a família, a proposta pedagógica” (P51). Nesta mesma direção, apontaram as diversas dificuldades que enfrentam como um modelo pedagógico ultrapassado que resulta em uma escola conteudista e uma má administração do trabalho de equipe (POZZOBON, MHENDRA, MARIN, p. 392, 2017).

Durante os relatos orais e escritos dos discentes de Letras, observamos uma preocupação pela busca por resultados melhores em Língua Portuguesa, principalmente com o conteúdo a ser ministrado a fim de privilegiar os tópicos cobrados nas avaliações sistêmicas de larga escala. Os discentes revelaram que o professor de Língua Portuguesa é levado a preparar seus estudantes para as avaliações sistêmicas, tornando-se assim o currículo vigente da disciplina. Esse movimento foi descrito na pesquisa de dissertação de Pereira (2015) que evidencia essa preocupação, a pesquisa é intitulada PAEBES: modos, formas e diálogos a partir dos usos dos resultados em Língua Portuguesa da avaliação externa estadual no município de Cariacica-ES. Assim:

É evidenciado um discurso homogeneizante por parte da equipe do Caed nas oficinas de apropriação e divulgação dos resultados, que abstrai o contexto social e silencia o trabalho dos professores e pedagogos nas escolas. A "preocupação" é como preparar melhor os estudantes para responder às metas estabelecidas pelos órgãos de controle. Assim, adaptar o estudante à realidade que não pode ser mudada e treiná-lo para viver nela (PEREIRA, 2015, p.138).

Dessa forma, corroboramos as ideias de Barreiro e Gebran (2006) quando afirmam que:

(...) a formação inicial e o estágio devem pautar-se pela investigação da realidade, por uma prática intencional, de modo que as ações sejam marcadas por processos reflexivos entre os professores-formadores e os futuros professores, ao examinarem, questionarem e avaliarem criticamente o seu fazer, o seu pensar e a sua prática (BARREIRO, GEBRAN, 2006, p. 21).

Assim, nossos discentes, ao chegarem à realidade da escola, passam a observar, examinar, questionar e avaliar as práticas desenvolvidas durante as aulas de Língua Portuguesa, confrontando muitas vezes com o que obtiveram quando estavam em suas escolas. Essa experiência nos faz ter a certeza de que a dicotomia entre teoria e prática não deve ser estanque, uma e outra são via de mão dupla, fazer-refazer, refletir-agir, pensar-elaborar-avaliar. São essas práticas que farão com que nossas aulas de Língua Portuguesa sejam interativas, sociais, inclusivas e motivadoras.

É importante destacar os procedimentos metodológicos de intervenção pedagógica propostos pelos discentes. Sob orientação de seus professores-tutores nas escolas-campo, os discentes puderam, a partir da observação e coparticipação, elaborar sua proposta de intervenção pedagógica, elencando os possíveis caminhos de reflexão e 
estratégias do que se poderia contribuir para a intervenção pedagógica, e assim colaborar com os desafios da realidade escolar. Diante dessa observação, no momento de planejamento com o professor-tutor, foram definidos os temas e gêneros a serem trabalhados com os estudantes das escolas. Após essa definição, os discentes apresentaram suas propostas de intervenção à professora orientadora do Estágio Supervisionado, que também pode mediar as reflexões e as sugestões de como proceder na intervenção pedagógica proposta. Segue um quadro-resumo do que foi proposto pelos discentes do Curso de Licenciatura em Letras/Português:

Quadro 1: Quadro Temático do Gênero Textual

\begin{tabular}{|c|c|c|}
\hline TEMA & EIXO & GÊNERO TEXTUAL \\
\hline Gravidez na adolescência. & Oralidade. & Debate regrado. \\
\hline Charges sobre dengue. & Escrita Conhecimentos & Convite e charge. \\
\hline $\begin{array}{l}\text { Convites para festa } \\
\text { comunitária. }\end{array}$ & Linguísticos e Gramaticais. & \\
\hline $\begin{array}{l}\text { Relato pessoal sobre minhas } \\
\text { travessuras. }\end{array}$ & $\begin{array}{l}\text { Escrita Conhecimentos } \\
\text { Linguísticos e Gramaticais. }\end{array}$ & Relato pessoal. \\
\hline Rimas e métricas. & Educação Literária. & Poesia e música. \\
\hline Memórias de um lugar. & Educação Literária. & Memórias literárias. \\
\hline $\begin{array}{l}\text { Estrutura e formação de } \\
\text { palavras. }\end{array}$ & $\begin{array}{l}\text { Escrita }- \text { Conhecimentos } \\
\text { Linguísticos e Gramaticais. }\end{array}$ & \\
\hline Textos Líricos. & Educação Literária. & Poesia. \\
\hline Cotidiano. & $\begin{array}{l}\text { Escrita }- \text { Conhecimentos } \\
\text { Linguísticos e Gramaticais. }\end{array}$ & Crônica. \\
\hline Cotidiano. & $\begin{array}{l}\text { Escrita }- \text { Conhecimentos } \\
\text { Linguísticos e Gramaticais. }\end{array}$ & Diário virtual. \\
\hline Questões étnico-raciais. & Educação Literária. & Poema. \\
\hline $\begin{array}{l}\text { Formação humanística: } \\
\text { amizade. }\end{array}$ & Leitura. Oralidade. & Comentário. \\
\hline Cotidiano. & $\begin{array}{l}\text { Escrita }- \text { Conhecimentos } \\
\text { Linguísticos e Gramaticais. }\end{array}$ & Diário. \\
\hline
\end{tabular}

Fonte: Elaborado pela autora

Além das propostas trazidas pelos discentes, para suas atividades docentes, podemos observar como seu olhar investigativo, no período de observação e coparticipação, foi importante para compreender o processo de ensino-aprendizagem. $\mathrm{O}$ relato abaixo demonstra uma prática recorrente, não só nas aulas de Língua Portuguesa, mas também nas demais disciplinas curriculares. Os estudantes "não têm paciência de ler as questões", trata-se de uma coparticipação na correção de uma avaliação, vejamos a análise realizada:

Foi realizada a correção das avaliações de Língua Portuguesa. Constatamos por meio dos resultados que muitos alunos erraram questões simples, como destacar o verbo num texto. Além disso, havia uma questão que exigia uma resposta pessoal e a grande maioria dos alunos errou ou copiou do texto, ipsis litteris. Apreendemos que, em muitos casos os alunos simplesmente não leem as questões ou simplesmente decodificam, mas não compreendem. O que parece é que o aluno não tem foco e nem paciência para ler e interpretar os enunciados, acarretando, dessa forma, respostas equivocadas. Ademais, a falta de leitura de textos diversos impossibilita a construção de conhecimento (Discente do $7^{\circ}$ período 2019/2, grifos da autora). 
Percebemos que nossos discentes conseguem fazer a leitura crítica da realidade que se apresenta, sabem também que há teorias que embasam esse entendimento. No entanto, o mais importante disso tudo é o que fazer diante de uma realidade tão desafiadora, na sua formação inicial, e para que não o desanime diante da profissão. Sabemos que:

[...] a compreensão da leitura não é um simples ato de identificação de informações, mas uma construção de sentidos com base em atividades inferenciais. Para se compreender bem um texto, tem-se que sair dele, pois o texto sempre monitora o seu leitor para além de si próprio e este é um aspecto notável quanto à produção de sentido (MARCUSCHI, 2011, p. 90).

Diante disso, reiteramos que o maior desafio na formação inicial docente é o olhar investigativo-reflexivo-sensível para levar para a sala de aula o que possa ser relevante ao ensino da língua. Tornando-o protagonista de seu momento, fazendo compreender o seu papel e transformar sua realidade.

Passamos para o último passo do nosso percurso do Estágio Supervisionado em um Curso de Licenciatura em Língua Portuguesa, que trata da docência de nosso discente. Após um período em observação e coparticipação, esse discente propõe uma intervenção pedagógica, orientado pelo professor-tutor e mediado pelo professororientador.

Compreendemos o momento da docência como um momento enriquecedor, em que há um movimento de se perceber um futuro professor e das responsabilidades inerentes a essa função. Como dito anteriormente, a disciplina Estágio Supervisionado possui etapas de atividades a se cumprir, uma delas é a docência compartilhada e regência de classe, em que o discente sob a orientação do professor-tutor ministra aulas práticas. Como etapa de socialização desse momento com os demais colegas, realizamos uma atividade intitulada: Seminário Estágio Supervisionado: Diálogos e Vivências dos cotidianos escolares. Nesse momento, os discentes do Curso de Licenciatura em LetrasPortuguês tiveram a oportunidade de explanar o desenvolvimento de suas práticas pedagógicas, avaliação e análise dos resultados alcançados. Esse seminário foi acompanhado por outros docentes das demais áreas do curso de Letras, resultando em um processo satisfatório. Seguem alguns relatos da importância desse momento na escola.

\section{Relato 01}

"O estágio proporciona um ganho imensurável para o aluno, porque a partir dele se torna possível a aplicação das teorias aprendidas na academia na prática escolar" (Discente $6^{\circ}$ período 2019/1).

\section{Relato 02}

"No estágio busca-se uma prática em que o discente construa significados dentro do texto partindo do seu conhecimento de mundo, numa relação interativa. Eis o desafio!" (Discente $6^{\circ}$ p. 2019/1).

\section{Relato 03}

"Diante da experiência do estágio supervisionado, pude perceber o quanto este é importante para a formação docente. $\mathrm{O}$ primeiro contato com a escola, a relação com os discentes, com os 
professores, a diretora e funcionários, tudo é enriquecedor para a formação, principalmente a regência em sala de aula" (Discente do $6^{\circ}$ p. 2019/1).

\title{
Relato 04
}

"Consideramos o período de estágio supervisionado como uma experiência positiva, enriquecedora e desafiadora. Propiciou-nos uma aproximação significativa com a prática docente. Serviu para reafirmar nosso pensamento de que não formamos apenas estudantes, e sim sujeitos para a vida e para a cidadania" (Discentes do $6^{\circ} \mathrm{p}$ 2019/1).

\section{Relato 05}

"A experiência do estágio supervisionado agregou muitos conhecimentos para a caminhada docente. Muitas percepções foram salientadas durante esse período. Aprender a lidar com o próximo, aprender a planejar e aprender me reinventar" (Discente $6^{\circ}$ p. 2019/1).

\section{Relato 06}

"Após a realização do estágio supervisionado, pude perceber o tamanho da responsabilidade do docente. Conduzir o processo de ensino aprendizagem é desafiador, complexo e requer constantes estudos, formações e a reflexão de sua prática na sala de aula" (Discente do $6^{\circ}$ p. 2019/1).

Mediante esses relatos de experiências, percebemos que os discentes consideram importante o momento de vivência nas escolas-campo, conforme relatam "(...) é um ganho imensurável (...)" (cf. RELATO 01), “(...) buscar significados (...) (cf. RELATO 02), “(...) o primeiro contato com a escola (...)", “(...) formamos sujeitos para vida (...)", “(...) aprender a planejar, aprender a me reinventar (...) (cf. RELATO 03) e "(...) pude perceber o tamanho da responsabilidade (...)" (cf. RELATO 04). Podemos verificar que os discentes se apropriam da realidade em que se encontram, confrontando o que se é estudado no meio acadêmico, levando-os às reflexões e pensar no seu agir, como afirma Pimenta e Lima (2006, p.14):

\begin{abstract}
Esse conceito provoca, entretanto, algumas indagações: o que se entende por realidade? Que realidade é essa? Qual o sentido dessa aproximação? O aproximar-se seria uma observação minuciosa ou à distância? A aproximação à realidade só tem sentido quando tem conotação de envolvimento, de intencionalidade, pois a maioria dos estágios burocratizados, carregados de fichas de observação, está numa visão míope de aproximação da realidade. Isso aponta para a necessidade de um aprofundamento conceitual do estágio e das atividades que nele se realizam.
\end{abstract}

É importante destacar que os discentes puderam refletir, durante as nossas rodas de conversas e no Estágio Terapia, a maneira mais apropriada de dar luz às teorias estudadas e a realidade da escola. Ao perceberem que a docência se faz em uma constante reflexão de sua prática pedagógica, ouvimos relatos como esses: “(...) se torna possível a aplicação das teorias aprendidas na academia na prática escolar (...) (cf. RELATO 01), "Consideramos o período de estágio supervisionado como uma experiência positiva, enriquecedora e desafiadora. Propiciou-nos uma aproximação significativa com a prática docente (...)" (cf. RELATO 04). Assim, essas narrativas corroboram o nosso pensamento e o de Pimenta e Lima (2006, p. 14) que afirma: 
questioná-la criticamente, à luz de teorias. Essa caminhada conceitual certamente será uma trilha para a proposição de novas experiências.

Observa-se que os discentes buscaram ser realistas com a experiência vivida nas escolas-campo, uma vez que para sua maioria foi o primeiro contato com a sala de aula. É importante ressaltar que esses relatos são frutos de experiências de docência, sendo que muitos deles foram de enfrentamento aos desafios encontrados na realidade, frustações e inquietações que aconteceram em nossas rodas de conversa, porém estes serão tema de um próximo estudo.

Esses trabalhos demonstram a importância de se fazer um Estágio Supervisionado visando à reflexão, à investigação e à ação de maneira a colaborar com o ensino-aprendizado dos estudantes nas escolas. Demostra, também, que apesar de pouco entendimento das complexidades inerentes à área de humanas, dentro de um contexto voltado para áreas de exatas, é possível desenvolver um trabalho de qualidade e equidade na formação inicial docente. Mesmo com a vida corrida de um discente que precisa trabalhar e estudar à noite vê-se uma possibilidade de transformação em sua vida e na do outro. Acreditamos que:

Por fim, o estágio supervisionado é um espaço da práxis, onde teoria e prática dialogam e se transformam. As experiências vivenciadas ali, mediadas pela reflexão sobre o fazer, permitem rupturas e leituras renovadas das práticas cotidianas, contribuindo para a formação de um professor mais competente e capaz de desenvolver um trabalho de qualidade (RODRIGUES, 2015, grifos da autora).

Portanto, as experiências vivenciadas, a reflexão, a teoria e a prática, o (des)fazer e o (re)inventar-se fazem parte da formação docente diante de um desafio cada vez maior na educação brasileira em todos os seus níveis, contextos sócio-econômicosociais. Acredita-se que estamos em um caminho direcionado à responsabilidade, ao planejamento e à qualidade do que se é prestado para a comunidade. Traz-nos a esperança que “(...) não tem nada que ver com sonho, utopias, conscientização e sim com a formação técnica, científica, profissional do educando" (FREIRE, 2004, p. 29)

\section{Considerações Finais}

Buscamos nesse trabalho dar visibilidade às ações realizadas na disciplina Estágio Supervisionado em um Curso de Licenciatura em Letras-Português no Instituto Federal do Espírito Santo, campus Venda Nova do Imigrante. Nesse processo de ensinoaprendizagem, sabemos que os desafios são enormes. Logo, nesse sentido, precisamos buscar nossa voz no meio acadêmico para obtermos apoio para superar nossas angústias.

Como proposta, vemos a necessidade de um fórum exclusivo para o Estágio Supervisionado em Licenciatura dentro da instituição, uma vez que as demandas e as dinâmicas são diferenciadas dos demais estágios supervisionados de nível técnico e de graduação das demais áreas do conhecimento.

Acreditamos na potencialidade do Estágio Supervisionado como um caminho para a formação do futuro professor, para que este possa, por meio da análise, do olhar investigativo e crítico transformar o seu fazer pedagógico em uma aula significativa para 
seus estudantes. Na fase de Estágio, é esperado que os discentes façam propostas de intervenção enriquecendo e amadurecendo, assim, seu olhar crítico e sua formação (PIMENTA; LIMA, 2012).

Como vimos, visando preparar melhor o futuro docente, o período do Estágio Supervisionado aos discentes é relevante porque compreendemos que somos sujeitos inacabados e eternos aprendizes, uma vez que o professor é um eterno pesquisador de suas práticas, quer seja no campo científico quanto educativo (DEMO, 2004).

Acreditamos que a busca da construção de saber é contínua/continuada, uma vez que há o que se aprender sempre. Dessa forma, é importante que o futuro docente tenha o entendimento de sempre se atualizar com a finalidade de acompanhar as discussões e debates acadêmicos (TARDIF, 2002). Assim, o Estágio Supervisionado pode contribuir para a compreensão das novas organizações de conhecimentos nos diversos contextos educacionais e possibilitando a reflexão de se fazer melhor no processo de ensinoaprendizagem na formação inicial docente (IMBERNÓN, 2004).

Ainda há muito que se pensar, refletir, buscar, para a construção do fazer-ser no processo de formação inicial de professores. Consideramos que o Estágio Supervisionado seja uma possibilidade de reflexão-ação-produção, não só como uma disciplina de atividade teórica e intrumentalizadora, mas também reflexiva com a realidade escolar, como concluem Pimenta e Lima (2006, p. 15):

\footnotetext{
Conclui que o estágio, nessa perspectiva, ao contrário do que se propugnava, não é atividade prática, mas atividade teórica, instrumentalizadora da práxis docente, entendida esta como a atividade de transformação da realidade. Nesse sentido, o estágio atividade curricular é atividade teórica de conhecimento, fundamentação, diálogo e intervenção na realidade, este sim objeto da práxis. Ou seja, é no trabalho docente do contexto da sala de aula, da escola, do sistema de ensino e da sociedade que a práxis se dá.
}

Há muitos caminhos a serem percorridos e temos consciência de que os desafios são enormes diante das condições da educação pública brasileira. Viver a escola e suas realidades, conviver com as histórias de vida dos sujeitos que fazem parte e pulsam a escola, poder promover a reflexão, o debate, o olho no olho, ser leitor e criador de suas imaginações, só uma escola pode ser capaz de realizar isso para um jovem aprendiz de professor.

\section{Referências}

BARREIRO, I. M. F.; GEBRAN, R. A. Prática de Ensino e Estágio Supervisionado na Formação de Professores. São Paulo: Avercamp, 2006.

BRASIL. Lei $N^{o}$. 9.394, de 20 de dezembro de 1996. Estabelece as diretrizes e bases da educação nacional. 1996. Brasília: Casa Civil/Subchefia para Assuntos Jurídicos, 1996.

FREIRE, P. À sombra da mangueira. São Paulo: Olho d'água, 2004.

IMBERNÓN, F. Formação Docente e Profissional: formar-se para a mudança e a incerteza. $5^{\circ}$ ed. São Paulo: Cortez, 2005. 
MARCUSCHI, L. A. Compreensão textual como trabalho criativo. In: Caderno de formação: formação de professores didática geral. São Paulo: Cultura Acadêmica, 2011, p.89-103, v.11.

MINISTÉRIO DA EDUCAÇÃO. Instituto Federal de Educação, Ciência e Tecnologia do Espírito Santo. Conselho Superior. Resolução $N^{o} 58$ de 17 de dezembro de 2018. Aprova a regulamentação dos estágios dos alunos da Educação Profissional Técnica de Nível Médio e da Educação Superior do Ifes.

PEREIRA, S. L. A. PAEBES: modos, formas e diálogos a partir dos usos dos resultados em Língua Portuguesa da avaliação externa estadual no município de Cariacica-ES. 2015. 233 f. Dissertação (Mestrado em Educação) - Universidade Federal do Espírito Santo, Vitória, 2015.

PIMENTA, S. G., LIMA, M. S. L. Estágio e docência: diferentes concepções. Revista Poíesis -Volume 3, Números 3 e 4, 2005/2006. p. 5-24.

PIMENTA, S. G.; LIMA, M. S. L. Estágio e docência. 4. ed. São Paulo: Cortez, 2012.

PAVAN, R. A necessidade de redizer e reviver a pedagogia da esperança de Paulo Freire. Revista e-Curriculum, São Paulo, v.16, n.4, out./dez.2018, p. 1437-1456.

POZZOBON M., MAHENDRA F., MARIN A. H. Renomeando o fracasso escolar. Psicologia Escolar e Educacional, SP. Volume 21, Número 3, Setembro/Dezembro de 2017: 387-396.

RODRIGUES, M. A. N. Estágio Supervisionado e a formação de professor: uma reflexão sobre integração teoria e prática. \#Tear Revista de Educação Ciência e Tecnologia, Canoas, v.4, n.2, 2015.

TARDIF, M. Saberes Docentes e Formação Profissional. Petrópolis, RJ. Editoras Vozes, 2002.

Recebido em 31 de maio de 2020

Aceito em 22 de junho de 2020 